\title{
Genetic Associations in Acquired Immune-Mediated Bone Marrow Failure Syndromes: Insights in Aplastic Anemia and Chronic Idiopathic Neutropenia
}

\author{
Irene Mavroudi and Helen A. Papadaki \\ Department of Hematology, University of Crete School of Medicine, P.O. Box 1352, 71110 Heraklion, Crete, Greece \\ Correspondence should be addressed to Helen A. Papadaki, epapadak@med.uoc.gr
}

Received 16 June 2012; Accepted 6 August 2012

Academic Editor: Mohammed Tikly

Copyright ( 2012 I. Mavroudi and H. A. Papadaki. This is an open access article distributed under the Creative Commons Attribution License, which permits unrestricted use, distribution, and reproduction in any medium, provided the original work is properly cited.

\begin{abstract}
Increasing interest on the field of autoimmune diseases has unveiled a plethora of genetic factors that predispose to these diseases. However, in immune-mediated bone marrow failure syndromes, such as acquired aplastic anemia and chronic idiopathic neutropenia, in which the pathophysiology results from a myelosuppressive bone marrow microenvironment mainly due to the presence of activated T lymphocytes, leading to the accelerated apoptotic death of the hematopoietic stem and progenitor cells, such genetic associations have been very limited. Various alleles and haplotypes of human leucocyte antigen (HLA) molecules have been implicated in the predisposition of developing the above diseases, as well as polymorphisms of inhibitory cytokines such as interferon- $\gamma$, tumor necrosis factor- $\alpha$, and transforming growth factor- $\beta 1$ along with polymorphisms on molecules of the immune system including the T-bet transcription factor and signal transducers and activators of transcription. In some cases, specific polymorphisms have been implicated in the outcome of treatment on those patients.
\end{abstract}

\section{Introduction}

Autoimmune diseases have been in the spotlight over the years and many of them seem to share similar underlying pathophysiology and immunogenetic mechanisms resulting from the interaction of multiple genetic and environmental factors [1-5]. Numerous genome-wide association studies have proven to be a useful tool in revealing the involvement of chromosomal loci that are associated with susceptibility to specific disorders $[6,7]$. However, in the distinct but nonetheless related group of immunomediated bone marrow (BM) failure syndromes, there is an underexplored field of genetic associations. In this paper we will highlight such associations focusing on two diseases which share similar immunopathologic features, namely acquired aplastic anemia (AA) and chronic idiopathic neutropenia (CIN), both belonging to the group of BM failure syndromes.

\section{Aplastic Anemia}

2.1. Pathogenetic Features. Acquired AA is a disease characterized by a hypoplastic or aplastic BM and peripheral pancytopenia of a varying degree [8]. Although in some AA patients viral infection, drug, or chemical exposure can be linked to the disease pathogenesis, in most cases the underlying etiology remains elusive. However, numerous studies have unveiled the role of $\mathrm{T}$ lymphocytes in the pathogenesis of AA. Specifically, it has been shown that oligoclonally expanded self-reactive T cells [9-11] induce apoptosis of hematopoietic stem/progenitor cells [12]; this can be mediated either through an interaction via the Fas/Fas-ligand (FasL) pathway $[13,14]$ or by the production of proinflammatory and growth inhibitory cytokines such as tumor necrosis factor- $\alpha$ (TNF- $\alpha$ ) and interferon- $\gamma$ (IFN- $\gamma$ ) [15-19], thus resulting in a depletion of the hematopoietic stem cell pool in the BM. Other immune cells and molecules have been also implicated in the pathogenesis of acquired AA and have been reviewed elsewhere $[20,21]$. The guidelines of treatment of AA suggest either hematopoietic stem cell transplantation (HSCT), which can cure the disease but it is not applicable to all patients, and/or immunosuppressive treatment (IST) with antithymocyte globulin (ATG) and/or cyclosporine A (CsA) [22-25]. The responsiveness of a 
significant proportion of AA patients to immunosuppressive therapy gives further evidence for the underlying immune pathophysiology of the disease and classifies it in the wide spectra of autoimmune diseases $[20,26]$. However, in several cases of IST-treated patients, the development of clonal disease has been the most serious complication, where the expansion of clones and clonal progression has been attributed to an immune selection and immunological escape $[27,28]$.

\subsection{Genetic Factors in Aplastic Anemia}

2.2.1. HLA Molecules. The human leukocyte antigen (HLA) is the most polymorphic genetic system. Its genes reside on chromosome 6 and determine HLA class I molecules encoded by HLA-A, HLA-B, and HLA-C loci, as well as HLA class II molecules encoded by HLA-DRA, -DRB1, -DRB3, -DRB4, -DRB5, -DQA1, -DQB1, -DPA1, and -DPB1 loci [29]. Given the fact that oligoclonally expanded $T$ cells are involved in the pathophysiology of acquired AA [9-11] and since the interaction between $\mathrm{CD}^{+}{ }^{+}$or $\mathrm{CD}_{4}^{+}$and their targets is mediated by HLA class I or II peptides, respectively, it has been suspected that polymorphic loci of these genes would be implicated in the susceptibility to the disease. Indeed, over the years various groups have tested this hypothesis in distinct populations and ethnicities.

By serological and molecular typing, it has been shown in a number of studies that HLA-DR2 was the gene associated with susceptibility to AA and in particular HLA-DRB $1 * 15$ allele in Chinese, Japanese, and Caucasians of different ethnicities [30-34] although there have been some contradicting facts [35]. Furthermore, it has been found that the HLA$\mathrm{DRB} 1 * 1501$ and not the HLA-DRB1 $* 1502$ allele was the one associated with an increased risk of developing AA $[31,36,37]$ despite the fact that in a group of Japanese patients the DRB $1 * 1502$ allele showed increased frequency, attributed mainly to the older age group [38]. However, only patients bearing the HLA-DRB $* 1501$ allele and interestingly the DRB $1 * 1501-\mathrm{DQA} 1 * 0102-\mathrm{DQB} 1 * 0602$ haplotype had a better response to CsA treatment $[31,38]$.

Other HLA alleles predisposing to development of AA have also been investigated. In a case report, the HLADRB $1 * 0405$ allele was a candidate gene for susceptibility to AA [39], while in another study, high-resolution genotyping of HLA-DRB 1 showed that the HLA-DRB $1 * 04$ allele coding for alanine at position 74 (HLA-DR4-Ala74) predisposed to severe AA (SAA) independently from the DRB $1 * 1501$ risk allele [40]. Furthermore, the DRB $1 * 04$ alleles had a worse response to CsA and a tendency to a poor prognosis. The HLA-DRB $* 07$ allele has been reported overexpressed in AA patients with no difference between adults and children, placing it as a susceptible allele for AA, at least in that cohort of Iranian subjects [35]. In addition, other candidate alleles predisposing to AA and SAA in children have been reported such as HLA-B $* 48: 01$, HLA-DRB $1 * 09: 01$, and HLA-B14 [41, 42]. However, in the latter study [42], it was demonstrated that different HLA associations occur in children and adults; therefore any assumptions regarding HLA allele distribution between these groups should be made cautiously.
Beside risk alleles, there have been studies revealing the possible protective role of HLA variants in developing AA. The allele HLA-DRB $1 * 13$ appeared to be protective in SAA children of Turkish origin [43], as well as the HLA$\mathrm{DRB} 1 * 03: 01, \mathrm{HLA}-\mathrm{DRB} 1 * 11: 01$, and HLA-B $* 51: 01$ alleles in Chinese children with AA [41]. Likewise, in a small cohort of Pakistani AA patients, HLA-DRB $* 03$ had higher frequency in controls suggesting a putative protective role [33]. In addition, in the Korean population, the DRB $1 * 1302$ allele has been found significantly lower in the group of SAA patients compared to controls or non-SAA patients [36]. However, in the previously mentioned study, the haplotype $\mathrm{A} * 31-\mathrm{B} * 51-\mathrm{DRB} 1 * 13$ was associated with predisposition to AA along with the $\mathrm{A} * 02-\mathrm{B} * 40-\mathrm{DRB} 1 * 15$ and $\mathrm{A} * 33$ $\mathrm{B} * 58$-DRB $1 * 15$ haplotypes [33].

In a large-scale single-nucleotide polymorphism (SNP) array-based study concerning a Japanese AA patient cohort, copy number-neutral loss of heterozygosity (CNN-LOH) of the $6 \mathrm{p}$ arm $(6 \mathrm{pLOH})$ was detected in a substantial proportion of patients [44]. The HLA-A $* 02: 01$, HLA-A $* 02: 06$, HLA$A * 31: 01$, and HLA-B $* 40: 02$ alleles were overrepresented in this population, and in the $6 \mathrm{pLOH}(+)$ clones, the missing HLA alleles were biased towards the four alleles mentioned above. This observation has led to the hypothesis that since cytotoxic $\mathrm{T}$ cells that presumably target antigen(s) present on hematopoietic stem cells through specific HLA class I molecules, $6 \mathrm{pLOH}(+)$ cell clones found in AA patients may have been derived by a progent that managed to escape the autoimmune attack by effectively deleting the risk of HLA species responsible for the immune insult. However, this escape mechanism from autoreactive cytotoxic $\mathrm{T}$ cells could not render $6 \mathrm{pLOH}(+)$ stem cells able to repopulate the BM effectively, unless immunosuppressive treatment was applied. The later observation was possibly due to the presence of inhibitory cytokines such as IFN- $\gamma$ and TNF- $\alpha$ in the BM of AA patients [44]. Nevertheless, future studies should be designed to shed light into the origin of autoimmunity, predisposition to the disease, and outcome of treatment regarding the thousands of HLA variants and the different emerging haplotypes in distinct ethnic populations.

2.2.2. Myelosuppressive Cytokines and Molecules. Elevated levels of inhibitory cytokines such as IFN- $\gamma$ and TNF- $\alpha$ as well as elevated levels of Fas antigen on $\mathrm{CD} 34^{+}$progenitor cells in the BM of AA patients have been previously reported to play a key role in the pathophysiology of the disease [13, 45-47]. Polymorphisms in such cytokines have been investigated by various groups in order to expose a genetic predisposition to AA or the outcome of IST.

The TNF- $\alpha$ gene -308 promoter/enhancer polymorphism, and specifically the TNF2 allele $(-308 \mathrm{~A})$, has been associated with elevated TNF- $\alpha$ levels [48] and has been shown to be overrepresented in a SAA Chinese population, contributing to the susceptibility to the disease in a DR3- and DR4-independent manner [49]. However, no susceptibility was demonstrated in milder forms of AA [49], which is consistent with other observations where the distribution of the TNF2 allele did not differ between AA patients 
and controls [50, 51]. Nevertheless, there are contradicting observations where the specific -308 AA TNF- $\alpha$ genotype was overrepresented in the AA group of patients [52]. Likewise, although in a German group the response to immunosuppressive therapy due to this rare allele was better even after 3 months of treatment compared to noncarriers [50], in another group such association was not demonstrated [51]. The different outcomes of the studies might be attributed to the low number of subjects tested and to variations due to a nonhomogenous population with AA of varying degree and different ethnicities.

The IFN $-\gamma+874 \mathrm{~A} / \mathrm{T}$ gene polymorphism, and in particular the +874TT genotype, has been shown to result in elevated levels of IFN- $\gamma$ production [53]. Many groups have demonstrated that the TT genotype is overrepresented in AA patients and correlates with susceptibility to the disease but not with the disease severity $[52,54-56]$. Moreover, it has been shown that the above specific genotype might predict a good response to IST [55]. Other polymorphisms such as the $-2,353 \mathrm{~A} / \mathrm{T}$ rs7139169 and the $-1,616 \mathrm{C} / \mathrm{T}$ rs2069705 have also been studied in AA, and it has been shown that the minor $\mathrm{T}$ allele of the former was protective and reduced the risk for AA, as well as the haplotype TCA regarding the polymorphisms in $-2,353,-1,616$, and +874 of IFN $\gamma$ gene. In addition, the above-mentioned $-2,353 \mathrm{~T}$ allele and TCA haplotype was shown to induce resistance to IST [51]. Polymorphisms of a CA repeat microsatellite sequence in the first intron of the IFN- $\gamma$ gene have been also shown to affect the production of IFN- $\gamma$. Specifically, homozygosity for the 12 (CA) repeats in position 1349 of the gene results in production of higher levels of IFN- $\gamma[53,57]$. The frequency of the 12-12 (CA) genotype as well as the single allele 12 in Caucasian and Chinese AA patients has been shown to be higher than controls, thus associating this variable number of dinucleotide repeat (VNDR) 1349 of IFN- $\gamma$ to the risk of AA $[57,58]$.

Transforming growth factor- $\beta 1$ (TGF- $\beta 1$ ) is another cytokine playing a role in hematopoiesis with multifunctional effects. In patients with aplastic anemia, the frequency of genotypes associated with high production of TGF- $\beta 1$ and in particular the -509 TT genotype was shown to be increased as opposed to controls [52, 56, 59]. This is in contrast to the fact that lower levels of TGF- $\beta 1$ have been described in the serum and in vitro cultures of AA patients [60]. However, the expression levels in the periphery do not always reflect the levels of locally expressed cytokines in the BM. Other polymorphisms of TGF- $\beta 1$ like $-590 \mathrm{C} / \mathrm{T}$ rs1800469 as well as the P10L C/T rs1800470 have been reported to play no role in the susceptibility to AA. However, the $\mathrm{T}$ allele of the P10L C/T, along with the CT haplotype regarding the above two polymorphisms, has demonstrated higher response to IST even at the third month of treatment compared to patients lacking this haplotype [51].

Polymorphisms of molecules like FAS and various interleukins (IL) such as IL-1 $\beta$, IL-2, IL-6, IL-10, and IL12 that have a role in the pathogenesis of AA have been investigated by different groups, but no significant difference was observed between patient groups and controls [51, 52, $56,59]$.
2.2.3. Other Immune Molecules. Increased expression of IFN- $\gamma$, TNF- $\alpha$, and IL- 2 from AA patients indicates that hematopoietic stem and progenitor cells are destroyed through a T-helper (Th) 1 cell response [61]. T-bet or TBX21 belongs to the T-box family of transcription factors, it is the key regulator of Th1 development and function, and it is found in Th1 but not in Th2 cells $[62,63]$. In patients with AA, T-bet is found elevated and transcribes actively the IFN- $\gamma$ gene [64]. TBX21 has been suggested as a common risk gene for a variety of autoimmune disorders $[65,66]$. Interestingly, the C allele of T-1993C, the TBX21 gene promoter, was associated with decreased risk in AA [67].

Signal transducer and activator of transcription 4 (STAT4) is a transcription factor binding to genes encoding T-bet and IFN- $\gamma$ and plays a critical role in Th1 and Th17 cell differentiation [68]. Polymorphisms of the STAT4 gene have been associated with various autoimmune diseases [69-71]; among the polymorphisms tested, the rs7574865 was a candidate common risk polymorphism. In a cohort of Chinese population, the rs7574865 polymorphism was found to pose as a candidate susceptibility gene, with an increased frequency of the T allele and THE TT genotype [67]. However, no association between the-above mentioned polymorphism and the response to IST was established.

Molecules that are expressed on $\mathrm{T}$ cells affecting selftolerance and autoreactivity have been extensively studied in autoimmune diseases. Cytotoxic T lymphocyte antigen 4 (CTLA4) is a molecule expressed on activated T cells that downregulates $\mathrm{T}$ cell autoreactivity [72]. Polymorphisms that result in a lower expression of CTLA4 $[73,74]$ have been associated with other autoimmune diseases [75]. Nonetheless, such associations were not observed in AA patients in a cohort of an Italian population [76].

Protein tyrosine phosphatase non-receptor-type 22 (PTPN22) gene encoding for a protein tyrosine phosphatase contributes to the modulation of negative $\mathrm{T}$ cell selection in the thymus and downregulation of autoreactive $\mathrm{T}$ cells in the periphery [77]. Although polymorphisms in this gene have been associated with autoimmune disorders [78], no contribution to the susceptibility in AA was observed, at least for the PTPN22 620W allele [79].

\section{Chronic Idiopathic Neutropenia}

3.1. Pathogenetic Features. Chronic idiopathic neutropenia (CIN) of adults is benign disorder of granulopoiesis representing the mild form of the spectrum of BM failure syndromes. It is an acquired form of neutropenia characterized by a prolonged and unexplained reduction in the number of circulating neutrophils below the lower limit of the normal distribution [80], although other forms of mild cytopenias might coexist $[81,82]$. Similar to AA, the pathogenetic cause of neutropenia in CIN is attributed to impaired BM granulopoiesis due to an inhibitory effect of the BM microenvironment consisting of activated $\mathrm{T}$ lymphocytes [83, 84 ] and monocytes [85], proinflammatory mediators, and proapoptotic cytokines such as TNF- $\alpha$, IL- $1 \beta$, TGF- $\beta 1$, IL6 as well as IFN- $\gamma$, and FasL $[80,83,84]$. It has been documented that progenitor and precursor cells, especially 
in the $\mathrm{CD} 34^{+} / \mathrm{CD}_{3} 3^{+}$compartment, are depleted through an apoptotic mechanism implicating the FAS/FasL as well as the CD40/CD40L pathways in the presence of TNF- $\alpha[86,87]$. Treatment of CIN patients with G-CSF administration is only recommended in the rare cases of patients suffering from severe or frequent infectious episodes [88].

\subsection{Genetic Factors in CIN}

3.2.1. HLA Molecules. The major HLA alleles have been typed in a small cohort of a genetically homogenous population in Crete, Greece [89]. Of all the alleles tested (HLA-A, -B, -C, -DRB1, -DQB1, and -DPB1), only the HLA-DRB1*1301 haplotype was significantly elevated in CIN patients as opposed to controls or other alleles. This was the first report of a genetic association to the predisposition of developing CIN. However, larger cohorts of patients need to be tested for a stronger association between HLA alleles and risk of CIN.

3.2.2. Myelosuppressive Cytokines and Molecules. The involvement of elevated proinflammatory and myelosuppressive cytokines such as TNF- $\alpha$, IL- $1 \beta$, IL-6, TGF- $\beta 1$ and FasL in the pathophysiology of CIN is well established $[83,90,91]$. A possible association between the elevated levels of the above soluble mediators and the genetic predisposition for CIN has been investigated by two different groups. Although the $-308 \mathrm{G} / \mathrm{A}$ polymorphism of the TNF- $\alpha$ gene, especially the TNF2 allele, had been previously shown to contribute to increased serum levels of this cytokine in other disease entities [92, 93], no association was identified between this polymorphism with either the occurrence or the severity of neutropenia in CIN subjects [94, 95]. Likewise, no difference in frequency of the $-511 \mathrm{C} / \mathrm{T}$ IL1B and the $+3953 \mathrm{C} / \mathrm{T}$ IL1B SNP or the variable number tandem repeat (VNTR) in intron 2 of IL-1Ra gene (IL1RN) was detected in CIN patients, [95] although these polymorphisms have been associated with IL1B gene expression and increased IL- $1 \beta$ production $[96,97]$. In the same cohort, the $-174 \mathrm{G} / \mathrm{C}$ SNP that has been associated with altered gene expression [98] failed to associate with CIN [95]. In the same context, the frequency of the $-844 \mathrm{~T} / \mathrm{C}$ SNP of the FasL gene was not associated with CIN [94].

Interestingly though, out of three SNPs on the TGF- $\beta 1$ gene, namely, the $-509 \mathrm{C} / \mathrm{T},+869 \mathrm{~T} / \mathrm{C}$, and the $+915 \mathrm{G} / \mathrm{C}$, the $-509 \mathrm{C} / \mathrm{T}$ and specifically the T allele and the TT genotype occurred in a statistically higher frequency in CIN patients thus associating this genotype with the risk of development of CIN. However, it did not associate with the severity of neutropenia. Nonetheless, patients with the CT or the TT genotype displayed elevated levels of TGF- $\beta 1$ in the serum or long-term BM cultures, indicating a contributory role of this cytokine in the pathophysiology of the disease [94].

\section{Closing Remarks}

Genetic factors that predispose to various disease states, including the acquired immune-mediated BM failure syndromes, may contribute to the pathophysiology of these disease entities. However, isolated SNPs are unlikely to be the only regulators of the complex mechanisms taking place in such autoimmune or immune-mediated conditions, but it is rather the specific combination of genotypes of cytokines and molecules on immune cells that predispose to AA and $\mathrm{CIN}$ and sustain the myelosuppressive BM microenvironment along with environmental factors. Wide-scale studies on different ethnic populations, with homogenous disease characteristics, would facilitate the systemic research for associations of genetic factors and disease risk.

\section{Authors' Contribution}

I. Mavroudi wrote the paper and H. A. Papadaki critically reviewed and revised the paper.

\section{Conflict of Interests}

No conflict of interest is declared by any of the authors.

\section{Acknowledgments}

This work was partly supported by an EU grant TransPOT (REGPOT FP7, Contract no. 285948) and a Grant 09SYN13-880 of the Greek Ministry of National Education and Religious Affairs.

\section{References}

[1] J. Heward and S. C. L. Gough, "Genetic susceptibility to the development of autoimmune disease," Clinical Science, vol. 93, no. 6, pp. 479-491, 1997.

[2] G. S. Cooper, F. W. Miller, and J. P. Pandey, "The role of genetic factors in autoimmune disease: implications for environmental research," Environmental Health Perspectives, vol. 107, supplement 5, pp. 693-700, 1999.

[3] P. Marrack, J. Kappler, and B. L. Kotzin, "Autoimmune disease: why and where it occurs," Nature Medicine, vol. 7, no. 8, pp. 899-905, 2001.

[4] J. M. Anaya, L. Gómez, and J. Castiblanco, "Is there a common genetic basis for autoimmune diseases?" Clinical and Developmental Immunology, vol. 13, no. 2-4, pp. 185-195, 2006.

[5] J. H. Cho and P. K. Gregersen, "Genomics and the multifactorial nature of human autoimmune disease," The New England Journal of Medicine, vol. 365, no. 17, pp. 1612-1623, 2011.

[6] C. Cotsapas, B. F. Voight, E. Rossin et al., "Pervasive sharing of genetic effects in autoimmune disease," PLoS Genetics, vol. 7, no. 8, Article ID e1002254, 2011.

[7] C. J. Lessard, J. A. Ice, I. Adrianto et al., "The genomics of autoimmune disease in the era of genome-wide association studies and beyond," Autoimmunity Reviews, vol. 11, no. 4, pp. 267-275, 2012.

[8] E. C. Guinan, "Diagnosis and management of aplastic anemia," Hematology, vol. 2011, no. 1, pp. 76-81, 2011.

[9] W. Zeng, S. Nakao, H. Takamatsu et al., "Characterization of T-cell repertoire of the bone marrow in immune-mediated aplastic anemia: evidence for the involvement of antigendriven T-cell response in cyclosporine-dependent aplastic anemia," Blood, vol. 93, no. 9, pp. 3008-3016, 1999.

[10] W. Zeng, J. P. Maciejewski, G. Chen, and N. S. Young, "Limited heterogeneity of $\mathrm{T}$ cell receptor BV usage in aplastic anemia," 
The Journal of Clinical Investigation, vol. 108, no. 5, pp. 765773, 2001.

[11] A. M. Risitano, H. Kook, W. Zeng, G. Chen, N. S. Young, and J. P. Maciejewski, "Oligoclonal and polyclonal CD4 and CD8 lymphocytes in aplastic anemia and paroxysmal nocturnal hemoglobinuria measured by $\mathrm{V} \beta$ CDR3 spectratyping and flow cytometry," Blood, vol. 100, no. 1, pp. 178-183, 2002.

[12] W. Zeng, G. Chen, S. Kajigaya et al., "Gene expression profiling in CD34 cells to identify differences between aplastic anemia patients and healthy volunteers," Blood, vol. 103, no. 1, pp. 325-332, 2004.

[13] J. P. Maciejewski, C. Selleri, T. Sato, S. Anderson, and N. S. Young, "Increased expression of Fas antigen on bone marrow CD34+ cells of patients with aplastic anaemia," British Journal of Haematology, vol. 91, no. 1, pp. 245-252, 1995.

[14] A. Luther-Wyrsch, C. Nissen, and A. Wodnar-Filipowicz, "Intracellular Fas ligand is elevated in T lymphocytes in severe aplastic anaemia," British Journal of Haematology, vol. 114, no. 4, pp. 884-890, 2001.

[15] N. C. Zoumbos, P. Gascon, J. Y. Djeu, and N. S. Young, "Interferon is a mediator of hematopoietic suppression in aplastic anemia in vitro and possibly in vivo," Proceedings of the National Academy of Sciences of the United States of America, vol. 82, no. 1, pp. 188-192, 1985.

[16] E. Sloand, S. Kim, J. P. Maciejewski, J. Tisdale, D. Follmann, and N. S. Young, "Intracellular interferon- $\gamma$ in circulating and marrow T cells detected by flow cytometry and the response to immunosuppressive therapy in patients with aplastic anemia," Blood, vol. 100, no. 4, pp. 1185-1191, 2002.

[17] S. Dubey, P. Shukla, and S. Nityanand, "Expression of interferon- $\gamma$ and tumor necrosis factor- $\alpha$ in bone marrow $\mathrm{T}$ cells and their levels in bone marrow plasma in patients with aplastic anemia," Annals of Hematology, vol. 84, no. 9, pp. 572577, 2005.

[18] C. Dufour, E. Ferretti, F. Bagnasco et al., "Changes in cytokine profile pre- and post-immunosuppression in acquired aplastic anemia," Haematologica, vol. 94, no. 12, pp. 1743-1747, 2009.

[19] W. Zeng, A. Miyazato, G. Chen, S. Kajigaya, N. S. Young, and J. P. Maciejewski, "Interferon- $\gamma$-induced gene expression in CD34 cells: identification of pathologic cytokine-specific signature profiles," Blood, vol. 107, no. 1, pp. 167-175, 2006.

[20] M. Stern, A. S. Buser, A. Lohri, A. Tichelli, and C. NissenDruey, "Autoimmunity and malignancy in hematologymore than an association," Critical Reviews in Oncology/Hematology, vol. 63, no. 2, pp. 100-110, 2007.

[21] J. P. Li, C. L. Zheng, and Z. C. Han, "Abnormal immunity and stem/progenitor cells in acquired aplastic anemia," Critical Reviews in Oncology/Hematology, vol. 75, no. 2, pp. 79-93, 2010.

[22] R. Gurion, A. Gafter-Gvili, M. Paul et al., "Hematopoietic growth factors in aplastic anemia patients treated with immunosuppressive therapy-systematic review and metaanalysis," Haematologica, vol. 94, no. 5, pp. 712-719, 2009.

[23] J. C. W. Marsh, S. E. Ball, J. Cavenagh et al., "Guidelines for the diagnosis and management of aplastic anaemia," British Journal of Haematology, vol. 147, no. 1, pp. 43-70, 2009.

[24] N. S. Young, A. Bacigalupo, and J. C. Marsh, "Aplastic anemia: pathophysiology and treatment," Biology of Blood and Marrow Transplantation, vol. 16, no. 1, supplement, pp. S119-S125, 2010.

[25] P. Scheinberg and N. S. Young, "How I treat acquired aplastic anemia," Blood, vol. 120, no. 6, pp. 1185-1196, 2012.
[26] N. S. Young, P. Scheinberg, and R. T. Calado, "Aplastic anemia," Current Opinion in Hematology, vol. 15, no. 3, pp. 162$168,2008$.

[27] M. G. Afable II, R. V. Tiu, and J. P. Maciejewski, "Clonal evolution in aplastic anemia," Hematology, vol. 2011, no. 1, pp. 90-95, 2011.

[28] M. G. Afable II, M. Wlodarski, H. Makishima et al., "SNP array-based karyotyping: differences and similarities between aplastic anemia and hypocellular myelodysplastic syndromes," Blood, vol. 117, no. 25, pp. 6876-6884, 2011.

[29] J. A. N. Klein and A. Sato, "The HLA system. First of two parts," The New England Journal of Medicine, vol. 343, no. 10, pp. 702-709, 2000.

[30] W. Shao, D. Tian, C. Liu, X. Sun, and X. Zhang, "Aplastic anemia is associated with HLA-DRB1* 1501 in Northern Han Chinese," International Journal of Hematology, vol. 71, no. 4, pp. 350-352, 2000.

[31] S. Nakao, H. Takamatsu, T. Chuhjo et al., "Identification of a specific HLA class II haplotype strongly associated with susceptibility to cyclosporine-dependent aplastic anemia," Blood, vol. 84, no. 12, pp. 4257-4261, 1994.

[32] M. Usman, S. N. Adil, T. Moatter, F. Bilwani, S. Arian, and M. Khurshid, "Increased expression of HLA DR2 in acquired aplastic anemia and its impact on response to immunosuppressive therapy," Journal of the Pakistan Medical Association, vol. 54, no. 5, pp. 251-254, 2004.

[33] S. Rehman, N. Saba, Khalilullah, S. Munir, P. Ahmed, and T. Mehmood, "The frequency of HLA class I and II alleles in Pakistani patients with aplastic anemia," Immunological Investigations, vol. 38, no. 8, pp. 812-819, 2009.

[34] J. Fernández-Torres, D. Flores-Jiménez, A. Arroyo-Pérez, J. Granados, and A. López-Reyes, "The ancestry of the HLA$\mathrm{DRB}^{*} 15$ allele predisposes the Mexican mestizo to the development ofaplastic anemia," Human Immunology, vol. 73, no. 8, pp. 840-843, 2012.

[35] F. Yari, M. Sobhani, M. Z. Vaziri, N. Bagheri, F. Sabaghi, and A. Talebian, "Association of aplastic anaemia and Fanconi's disease with HLA-DRB1 alleles," International Journal of Immunogenetics, vol. 35, no. 6, pp. 453-456, 2008.

[36] E. Y. Song, S. Park, D. S. Lee, H. I. Cho, and M. H. Park, "Association of human leukocyte antigen-DRB1 alleles with disease susceptibility and severity of aplastic anemia in Korean patients," Human Immunology, vol. 69, no. 6, pp. 354-359, 2008.

[37] J. S. Dhaliwal, L. Wong, M. A. Kamaluddin, L. Y. Yin, and S. Murad, "Susceptibility to aplastic anemia is associated with HLA-DRB1*1501 in an aboriginal population in Sabah, Malaysia," Human Immunology, vol. 72, no. 10, pp. 889-892, 2011.

[38] C. Sugimori, H. Yamazaki, X. Feng et al., "Roles of DRB1*1501 and DRB1*1502 in the pathogenesis of aplastic anemia," Experimental Hematology, vol. 35, no. 1, pp. 13-20, 2007.

[39] S. Nakao, A. Takami, H. Takamatsu et al., "Isolation of a T-cell clone showing HLA-DRB1*0405-restricted cytotoxicity for hematopoietic cells in a patient with aplastic anemia," Blood, vol. 89, no. 10, pp. 3691-3699, 1997.

[40] S. I. Kapustin, T. I. Popova, A. A. Lyshchov, E. N. Imyanitov, M. N. Blinov, and K. M. Abdulkadyrov, "HLA-DR4-Ala74 $\beta$ is associated with risk and poor outcome of severe aplastic anemia," Annals of Hematology, vol. 80, no. 2, pp. 66-71, 2001.

[41] C. Chen, S. Lu, M. Luo, B. Zhang, and L. Xiao, "Correlations between HLA-A, HLA-B and HLA-DRB1 allele polymorphisms and childhood susceptibility to acquired aplastic anemia," Acta Haematologica, vol. 128, no. 1, pp. 23-27, 2012. 
[42] M. Führer, J. Durner, G. Brünnler et al., "HLA association is different in children and adults with severe acquired aplastic anemia," Pediatric Blood and Cancer, vol. 48, no. 2, pp. 186191, 2007.

[43] F. S. Oguz, N. Yalman, A. S. Diler, R. Oguz, S. Anak, and M. T. Dorak, "HLA-DRB1* 15 and pediatric aplastic anemia," Haematologica, vol. 87, no. 7, pp. 772-774, 2002.

[44] T. Katagiri, A. Sato-Otsubo, K. Kashiwase et al., "Frequent loss of HLA alleles associated with copy number-neutral $6 \mathrm{pLOH}$ in acquired aplastic anemia," Blood, vol. 118, no. 25, pp. 66016609, 2011.

[45] A. Miura, K. Endo, T. Sugawara et al., "T cell-mediated inhibition of erythropoiesis in aplastic anaemia: the possible role of IFN- $\gamma$ and TNF- $\alpha$," British Journal of Haematology, vol. 78, no. 3, pp. 442-449, 1991.

[46] J. C. Schulz and N. T. Shahidi, "Detection of tumor necrosis factor- $\alpha$ in bone marrow plasma and peripheral blood plasma from patients with aplastic anemia," American Journal of Hematology, vol. 45, no. 1, pp. 32-38, 1994.

[47] C. Dufour, A. Corcione, J. Svahn, R. Haupt, N. Battilana, and V. Pistoia, "Interferon $\gamma$ and tumour necrosis factor $\alpha$ are overexpressed in bone marrow $\mathrm{T}$ lymphocytes from paediatric patients with aplastic anaemia," British Journal of Haematology, vol. 115, no. 4, pp. 1023-1031, 2001.

[48] L. J. Abraham and K. M. Kroeger, "Impact of the -308 TNF promoter polymorphism on the transcriptional regulation of the TNF gene: relevance to disease," Journal of Leukocyte Biology, vol. 66, no. 4, pp. 562-566, 1999.

[49] J. Peng, C. Liu, K. Zhu et al., "The TNF2 allele is a risk factor to severe aplastic anemia independent of HLA-DR," Human Immunology, vol. 64, no. 9, pp. 896-901, 2003.

[50] J. Demeter, G. Messer, and H. Schrezenmeier, "Clinical relevance of the TNF-alpha promoter/enhancer polymorphism in patients with aplastic anemia," Annals of Hematology, vol. 81, no. 10, pp. 566-569, 2002.

[51] Y. G. Lee, I. Kim, J. H. Kim et al., "Impact of cytokine gene polymorphisms on risk and treatment outcomes of aplastic anemia," Annals of Hematology, vol. 90, no. 5, pp. 515-521, 2011.

[52] V. Gidvani, S. Ramkissoon, E. M. Sloand, and N. S. Young, "Cytokine gene polymorphisms in acquired bone marrow failure," American Journal of Hematology, vol. 82, no. 8, pp. 721-724, 2007.

[53] V. Pravica, C. Perrey, A. Stevens, J. H. Lee, and I. V. Hutchinson, "A single nucleotide polymorphism in the first intron of the human IFN- $\gamma$ gene: absolute correlation with a polymorphic CA microsatellite marker of high IFN- $\gamma$ production," Human Immunology, vol. 61, no. 9, pp. 863-866, 2000.

[54] H. Chang, J. Y. Zhang, and W. T. Meng, "Single nucleotide polymorphism of interferon-gamma gene +874 T/A in patients with aplastic anemia," Zhongguo Shi Yan Xue Ye Xue Za Zhi, vol. 16, no. 2, pp. 325-327, 2008.

[55] H. Chang, F. Zeng, J. Y. Zhang et al., "Association of the interferon-gamma single nucleotide polymorphism +874 (T/A) with response to immunosuppressive therapy in patients with severe aplastic anemia," Blood Cells, Molecules, and Diseases, vol. 45, no. 4, pp. 313-316, 2010.

[56] B. Serio, C. Selleri, and J. P. Maciejewski, "Impact of immunogenetic polymorphisms in bone marrow failure syndromes," Mini-Reviews in Medicinal Chemistry, vol. 11, no. 6, pp. 544552, 2011.

[57] C. Dufour, M. Capasso, J. Svahn et al., "Homozygosis for (12) CA repeats in the first intron of the human IFN- $\gamma$ gene is significantly associated with the risk of aplastic anaemia in
Caucasian population," British Journal of Haematology, vol. 126, no. 5, pp. 682-685, 2004.

[58] J. Y. Zhang, H. Chang, and W. T. Meng, "The polymorphism of interferon gamma gene CA short tandem repeat is associated with aplastic anemia," Sichuan Da Xue Xue Bao Yi Xue Ban, vol. 39, no. 1, pp. 23-58, 2008.

[59] E. Fermo, P. Bianchi, W. Barcellini et al., "Immunoregulatory cytokine polymorphisms in Italian patients affected by paroxysmal nocturnal haemoglobinuria and aplastic anaemia," European Journal of Immunogenetics, vol. 31, no. 6, pp. 267269, 2004.

[60] S. Rizzo, S. B. Killick, S. Patel et al., "Reduced TGF- $\beta 1$ in patients with aplastic anaemia in vivo and in vitro," British Journal of Haematology, vol. 107, no. 4, pp. 797-803, 1999.

[61] N. C. Giannakoulas, M. Karakantza, G. L. Theodorou et al., "Clinical relevance of balance between type 1 and type 2 immune responses of lymphocyte subpopulations in aplastic anaemia patients," British Journal of Haematology, vol. 124, no. 1, pp. 97-105, 2004.

[62] S. J. Szabo, S. T. Kim, G. L. Costa, X. Zhang, C. G. Fathman, and L. H. Glimcher, "A novel transcription factor, T-bet, directs Th1 lineage commitment," Cell, vol. 100, no. 6, pp. 655-669, 2000.

[63] S. J. Szabo, B. M. Sullivan, C. Sternmann, A. R. Satoskar, B. P. Sleckman, and L. H. Glimcher, "Distinct effects of T-bet in Th1 lineage commitment and IFN- $\gamma$ production in CD4 and CD8 T cells," Science, vol. 295, no. 5553, pp. 338-342, 2002.

[64] E. E. Solomou, K. Keyvanfar, and N. S. Young, "T-bet, a Th1 transcription factor, is up-regulated in $\mathrm{T}$ cells from patients with aplastic anemia," Blood, vol. 107, no. 10, pp. 3983-3991, 2006.

[65] Y. You, W. Zhao, S. Chen et al., "Association of TBX21 gene haplotypes in a Chinese population with systemic lupus erythematosus," Scandinavian Journal of Rheumatology, vol. 39, no. 3, pp. 254-258, 2010.

[66] S. C. Chae, S. C. Shim, and H. T. Chung, "Association of TBX21 polymorphisms in a Korean population with rheumatoid arthritis," Experimental and Molecular Medicine, vol. 41, no. 1, pp. 33-41, 2009.

[67] M. Ge, Y. Zheng, X. Li et al., "The polymorphisms of $\mathrm{T}$ cell-specific TBX21 and STAT4 genes may contribute to the susceptibility of Chinese individuals to aplastic anemia," Human Immunology, vol. 73, no. 1, pp. 118-121, 2012.

[68] W. T. Watford, B. D. Hissong, J. H. Bream, Y. Kanno, L. Muul, and J. J. O'Shea, "Signaling by IL-12 and IL-23 and the immunoregulatory roles of STAT4," Immunological Reviews, vol. 202, pp. 139-156, 2004.

[69] A. Martínez, J. Varadé, A. Márquez et al., "Association of the STAT4 gene with increased susceptibility for some immunemediated diseases," Arthritis and Rheumatism, vol. 58, no. 9, pp. 2598-2602, 2008.

[70] K. E. Taylor, E. F. Remmers, A. T. Lee et al., "Specificity of the STAT4 genetic association for severe disease manifestations of systemic lupus erythematosus," PLoS Genetics, vol. 4, no. 5, Article ID e1000084, 2008.

[71] M. I. Zervou, G. N. Goulielmos, F. Castro-Giner, A. D. Tosca, and S. Krueger-Krasagakis, "STAT4 gene polymorphism is associated with psoriasis in the genetically homogeneous population of Crete, Greece," Human Immunology, vol. 70, no. 9, pp. 738-741, 2009.

[72] P. J. Noel, L. H. Boise, and C. B. Thompson, "Regulation of T cell activation by CD28 and CTLA4," Advances in Experimental Medicine and Biology, vol. 406, pp. 209-217, 1996. 
[73] A. Ligers, N. Teleshova, T. Masterman, W. X. Huang, and J. Hillert, "CTLA-4 gene expression is influenced by promoter and exon 1 polymorphisms," Genes and Immunity, vol. 2, no. 3, pp. 145-152, 2001.

[74] M. Mäurer, S. Loserth, A. Kolb-Mäurer et al., "A polymorphism in the human cytotoxic T-lymphocyte antigen 4 (CTLA4) gene (exon $1+49$ ) alters T-cell activation," Immunogenetics, vol. 54, no. 1, pp. 1-8, 2002.

[75] H. Ueda, J. M. M. Howson, L. Esposito et al., "Association of the T-cell regulatory gene CTLA4 with susceptibility to autoimmune disease," Nature, vol. 423, no. 6939, pp. 506-511, 2003.

[76] J. Svahn, M. Capasso, M. Lanciotti et al., "The polymorphism $-318 \mathrm{C}>\mathrm{T}$ in the promoter and $49 \mathrm{~A}>\mathrm{G}$ in exon 1 of CTLA4 and the risk of aplastic anemia in a Causasian population," Bone Marrow Transplantation, vol. 35, supplement 1, pp. S89S92, 2005.

[77] L. A. Criswell, K. A. Pfeiffer, R. F. Lum et al., "Analysis of families in the multiple autoimmune disease genetics consortium (MADGC) collection: the PTPN22 620W allele associates with multiple autoimmune phenotypes," The American Journal of Human Genetics, vol. 76, no. 4, pp. 561-571, 2005.

[78] S. A. Chung and L. A. Criswell, "PTPN22: its role in SLE and autoimmunity," Autoimmunity, vol. 40, no. 8, pp. 582-590, 2007.

[79] S. A. Graf, R. T. Calado, and N. S. Young, "PTPN22 620W allele is not associated with aplastic anemia," American Journal of Hematology, vol. 82, no. 4, pp. 291-292, 2007.

[80] H. A. Papadaki, J. Palmblad, and G. D. Eliopoulos, "Nonimmune chronic idiopathic neutropenia of adult: an overview," European Journal of Haematology, vol. 67, no. 1, pp. 35-44, 2001.

[81] M. Psyllaki, A. Damianaki, C. Gemetzi, K. Pyrovolaki, G. D. Eliopoulos, and H. A. Papadaki, "Impaired megakaryopoiesis in patients with chronic idiopathic neutropenia is associated with increased transforming growth factor $\beta 1$ production in the bone marrow," British Journal of Haematology, vol. 134, no. 6, pp. 624-631, 2006.

[82] C. Pontikoglou, G. Liapakis, K. Pyrovolaki et al., "Evidence for downregulation of erythropoietin receptor in bone marrow erythroid cells of patients with chronic idiopathic neutropenia," Experimental Hematology, vol. 34, no. 10, pp. 1312-1322, 2006.

[83] H. A. Papadaki, K. Stamatopoulos, A. Damianaki et al., "Activated T-lymphocytes with myelosuppressive properties in patients with chronic idiopathic neutropenia," British Journal of Haematology, vol. 128, no. 6, pp. 863-876, 2005.

[84] M. Spanoudakis, H. Koutala, M. Ximeri, K. Pyrovolaki, K. Stamatopoulos, and H. A. Papadaki, “T-cell receptor V $\beta$ repertoire analysis in patients with chronic idiopathic neutropenia demonstrates the presence of aberrant T-cell expansions," Clinical Immunology, vol. 137, no. 3, pp. 384-395, 2010.

[85] M. Velegraki, H. Koutala, C. Tsatsanis, and H. A. Papadaki, "Increased levels of the high mobility group box 1 protein sustain the inflammatory bone marrow microenvironment in patients with chronic idiopathic neutropenia via activation of toll-like receptor 4," Journal of Clinical Immunology, vol. 32, no. 2, pp. 312-322, 2012.

[86] H. A. Papadaki, A. G. Eliopoulos, T. Kosteas et al., "Impaired granulocytopoiesis in patients with chronic idiopathic neutropenia is associated with increased apoptosis of bone marrow myeloid progenitor cells," Blood, vol. 101, no. 7, pp. 2591-2600, 2003.
[87] I. Mavroudi, V. Papadaki, K. Pyrovolaki, P. Katonis, A. G. Eliopoulos, and H. A. Papadaki, "The CD40/CD40 ligand interactions exert pleiotropic effects on bone marrow granulopoiesis," Journal of Leukocyte Biology, vol. 89, no. 5, pp. 771783, 2011.

[88] H. A. Papadaki and C. Pontikoglou, "Pathophysiologic mechanisms, clinical features and treatment of idiopathic neutropenia," Expert Review of Hematology, vol. 1, no. 2, pp. 217-229, 2008.

[89] H. A. Papadaki, G. D. Eliopoulos, S. A. Coulocheri, M. Spyropoulou, and C. Stavropoulos-Giokas, "Increased frequency of HLA-DRB1*1302 haplotype in patients with nonimmune chronic idiopathic neutropenia of adults," Blood, vol. 97, no. 2, pp. 580-581, 2001.

[90] H. A. Papadaki, K. Giouremou, and G. D. Eliopoulos, "Low frequency of myeloid progenitor cells in chronic idiopathic neutropenia of adults may be related to increased production of TGF- $\beta 1$ by bone marrow stromal cells," European Journal of Haematology, vol. 63, no. 3, pp. 154-162, 1999.

[91] H. A. Papadaki, S. Coulocheri, and G. D. Eliopoulos, "Patients with chronic idiopathic neutropenia of adults have increased serum concentrations of inflammatory cytokines and chemokines," American Journal of Hematology, vol. 65, no. 4, pp. 271-277, 2000.

[92] A. G. Wilson, J. A. Symons, T. L. McDowell, H. O. McDevitt, and G. W. Duff, "Effects of a polymorphism in the human tumor necrosis factor alpha promoter on transcriptional activation," Proceedings of the National Academy of Sciences of the United States of America, vol. 94, no. 7, pp. 3195-3199, 1997.

[93] K. Warzocha, P. Ribeiro, J. Bienvenu et al., "Genetic polymorphisms in the tumor necrosis factor locus influence nonHodgkin's lymphoma outcome," Blood, vol. 91, no. 10, pp. 3574-3581, 1998.

[94] D. G. Eliopoulos, I. Mavroudi, C. Pontikoglou et al., "The $-509 \mathrm{C} / \mathrm{T}$ polymorphism of transforming growth factor- $\beta 1$ is associated with increased risk for development of chronic idiopathic neutropenia," European Journal of Haematology, vol. 83, no. 6, pp. 535-540, 2009.

[95] M. Addas-Carvalho, E. V. Paula, C. S. P. Lima, and S. T. O. Saad, "Polymorphisms of interleukin-1 gene complex, IL6 and tumour necrosis factor genes in chronic idiopathic neutropenia of adults," Annals of Hematology, vol. 84, no. 11, pp. 709-714, 2005.

[96] S. Santtila, K. Savinainen, and M. Hurme, "Presence of the IL-1RA allele $2\left(\mathrm{IL}_{\mathrm{RNN}}^{*} 2\right)$ is associated with enhanced IL-1 $\beta$ production in vitro," Scandinavian Journal of Immunology, vol. 47, no. 3, pp. 195-198, 1998.

[97] E. M. El-Omar, M. Carrington, W. H. Chow et al., "Interleukin-1 polymorphisms associated with increased risk of gastric cancer," Nature, vol. 404, no. 6776, pp. 398-402, 2000.

[98] D. Fishman, G. Faulds, R. Jeffey et al., "The effect of novel polymorphisms in the interleukin-6 (IL-6) gene on IL-6 transcription and plasma IL-6 levels, and an association with systemic-onset juvenile chronic arthritis," The Journal of Clinical Investigation, vol. 102, no. 7, pp. 1369-1376, 1998. 


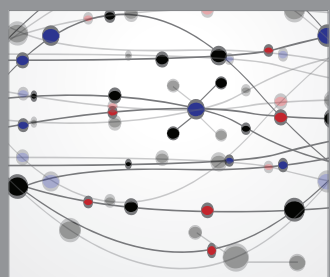

The Scientific World Journal
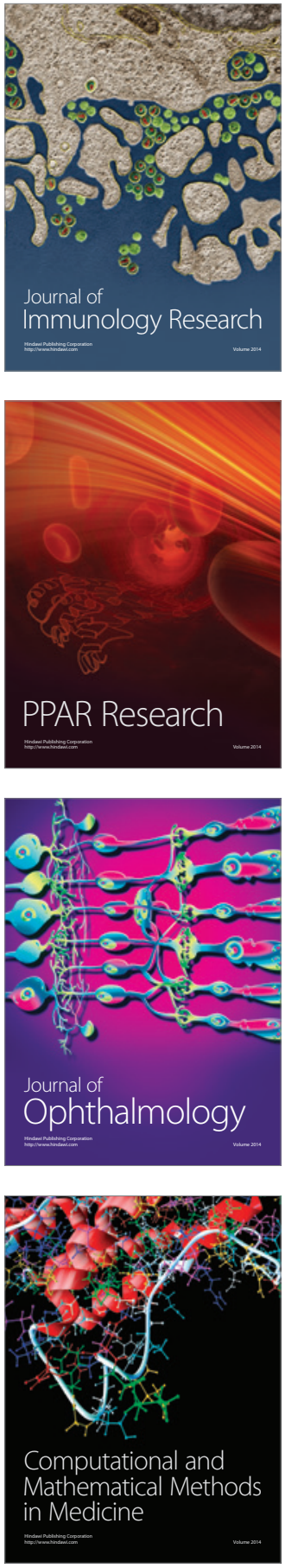

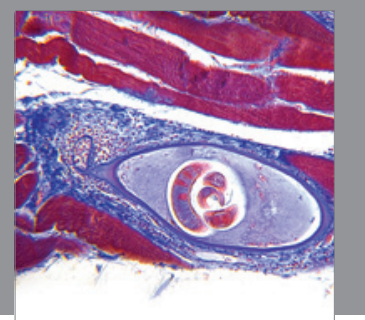

Gastroenterology

Research and Practice
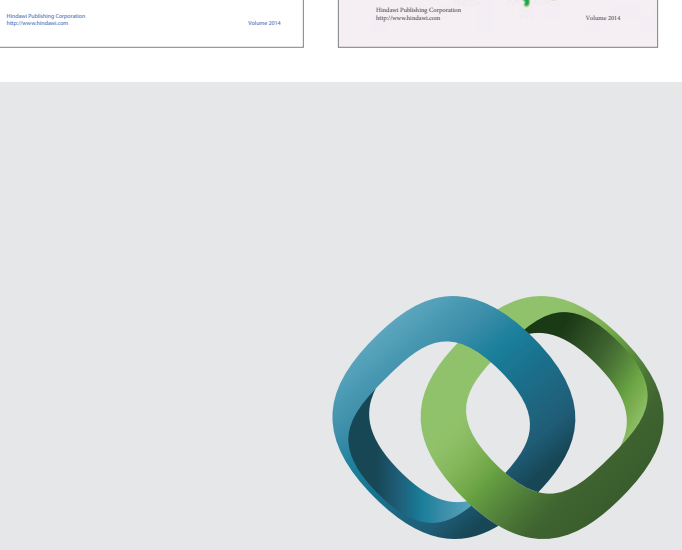

\section{Hindawi}

Submit your manuscripts at

http://www.hindawi.com
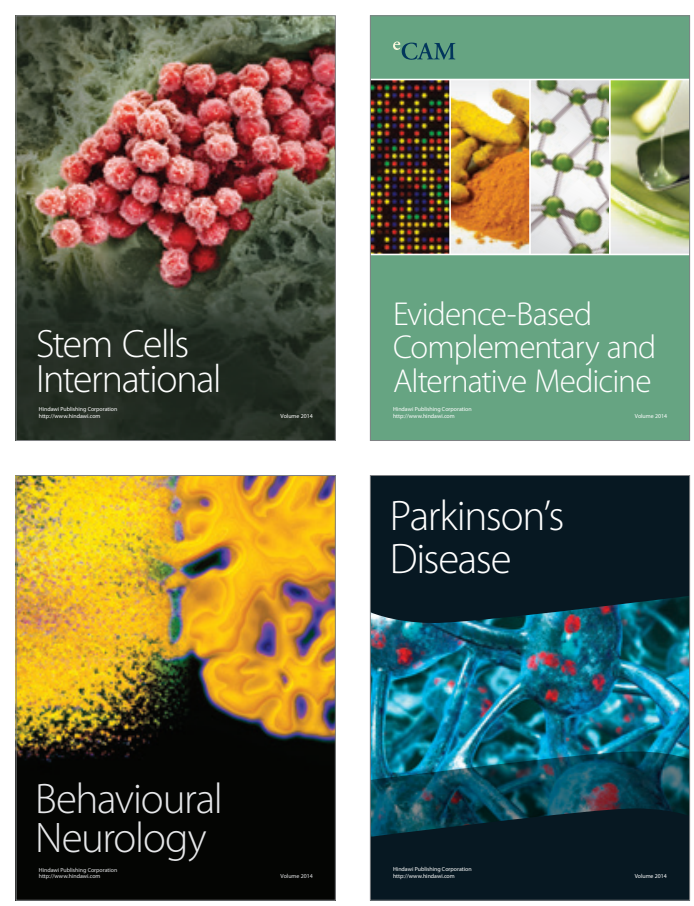

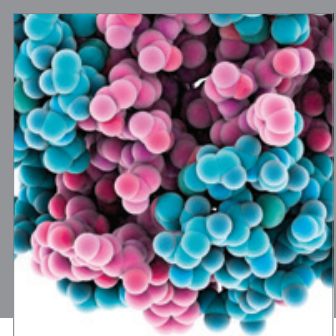

Journal of
Diabetes Research

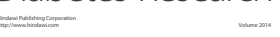

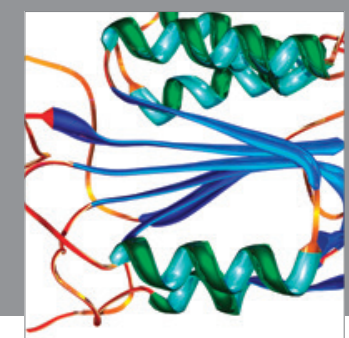

Disease Markers
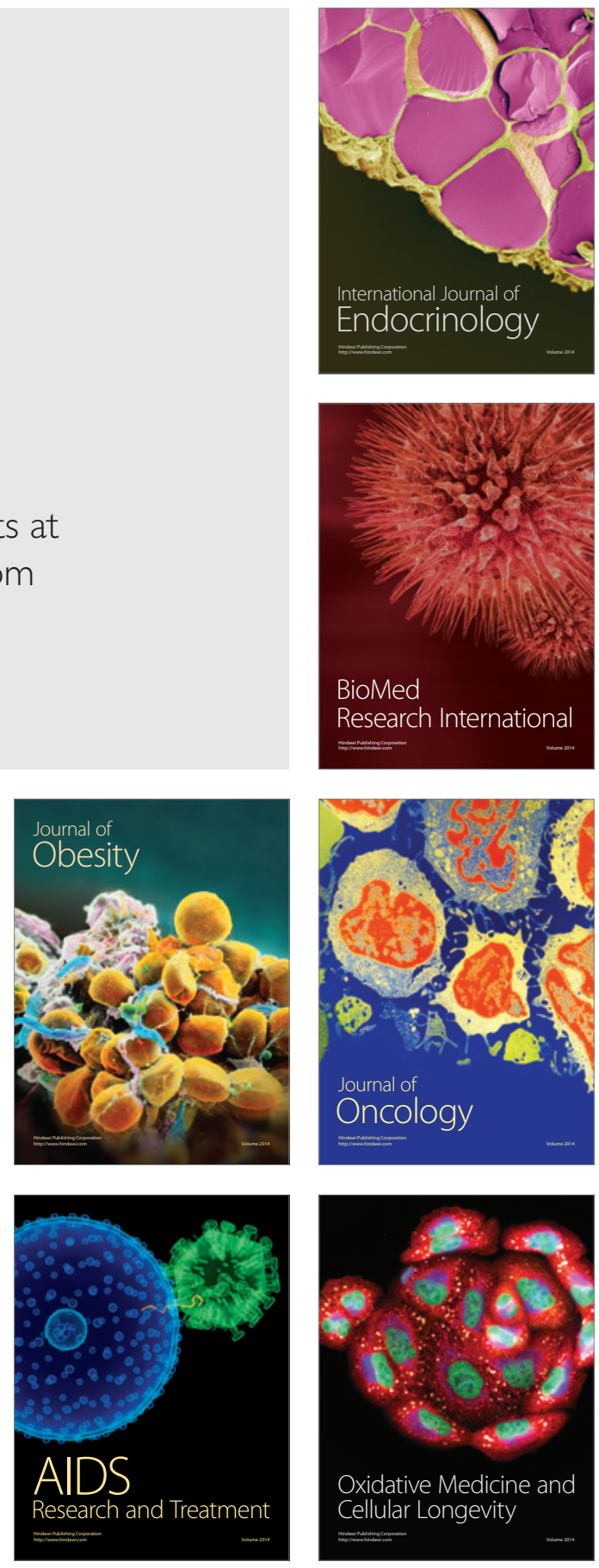